\author{
Ewelina Kwiatkowska \\ dr inż. \\ Politechnika Wrocławska \\ Katedra Mostów i Kolei \\ kwiatkowskae@interia.pl
}

DOI: $10.35117 /$ A_ENG_17_10_03

\title{
Quality and vibration isolation of Level crossing
}

\begin{abstract}
An analysis of level crossing quality on Polish railway lines was conducted. Describes the use of the guidelines in force at the level crossing railway lines. Analysis of the guidelines for the application of level crssing has shown the application to prefer the use of level crssing with ballast. An analysis of vibration isolation in level crssing was performed.
\end{abstract}

Keywords: Level crossing; Vibration isolation; Track quality

The surface on level crossings is aimed at providing safe and continuous vehicular and rail traffic. Ensuring full operational quality of the surface at railway and road crossings requires the use and renewal of the passage structure and railway surface. The construction of the pavement on crossings with full operational suitability ensures safe handling of traffic at the maximum planned speed. A journey with limited operational suitability requires the introduction of speed limits for the line and road, and the unserviceable journeys are excluded from traffic.

The quality of the exploited surface at crossings is determined by: reliability and durability of operation, maintenance and repair compliance and economic characteristics. The surface of level crossings, in addition to ensuring full operational quality, is aimed, in accordance with the Regulation of the Minister of Infrastructure and Development of 20 October 2015 on technical conditions to be met by the intersection of railway lines and railway sidings with roads and their location [1] $\S 31$, eliminate the harmful effect of vibrations on buildings located in the immediate vicinity of intersections and vibrations and noise to which people staying in these buildings will be exposed.

\section{Theory of vibration isolation of crossings}

The vibration isolation theory distinguishes between two cases of vibration isolation, consisting in limiting the transmission of dynamic force to the environment (power vibration insulation) and vibration isolation by limiting the impact of vibrations on the environment (displacement vibration isolation). In both cases of vibration isolation we deal with vibrations frequencies $\mathrm{f}<100 \mathrm{~Hz}$ and this results from the adopted model of the vibration isolation system as a discrete system with one degree of freedom. In the track surface, material vibrations occur in the frequency range $f=100 \div 5000 \mathrm{~Hz}$. Material vibrations should be taken into account when solving problems affecting the surroundings of rail and car communication.

Comparison of the traditional run construction with the vibration isolated construction can be carried out based on the dynamic analysis of the simplified physical models shown in Fig.1 [4]. 


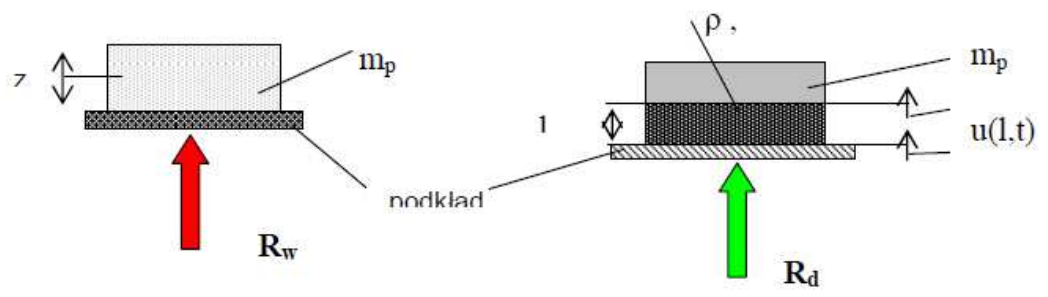

1. Physical models of traditional and vibration isolated trips [4]

An exemplary measure of the effectiveness of use in passing vibration isolation is the ratio of $\mathrm{Rw} / \mathrm{Rd}$ forces generated during the passage of vehicles, transferred to the ground by passing without the element of vibration and sound insulation and using such an element where: mpmass of concrete slab + vehicle mass, $\rho$ - density rubber plate, E - dynamic Young's modulus, $\mathrm{F}$ - rubber plate surface, 1 - rubber plate thickness, $\mathrm{u}(\mathrm{x}, \mathrm{t})$ - rubber plate deformation; $\mathrm{x}=(0$ or 1). Fig. 2 An exemplary energy balance of railway crossing with vibration isolation is presented [3].

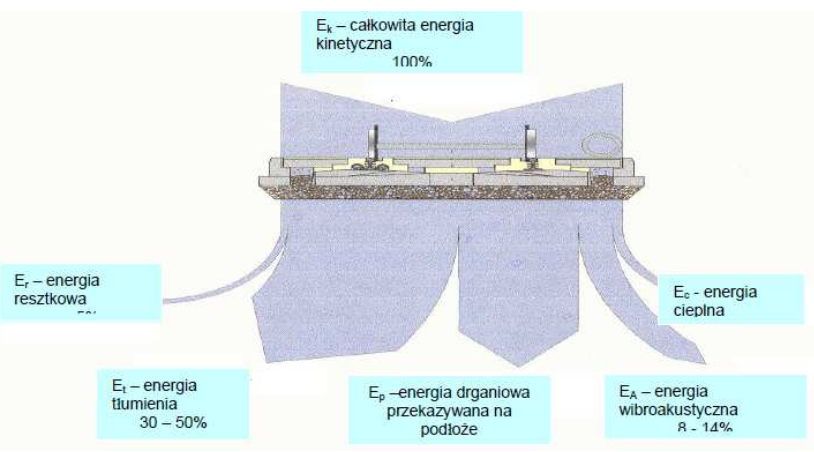

2. Energy balance of a vibration isolation railway crossing [3]

In the case of passing without vibration isolation, an exemplary energy balance presented in Fig. 3, illustrates the damping energy. The damping energy is contained in the energy transferred to the substrate, causing an increase in vibroacoustic energy. The vibroacoustic energy is the energy of acceleration and impact noise causing an increase in the noise level in the surrounding level crossing environment.

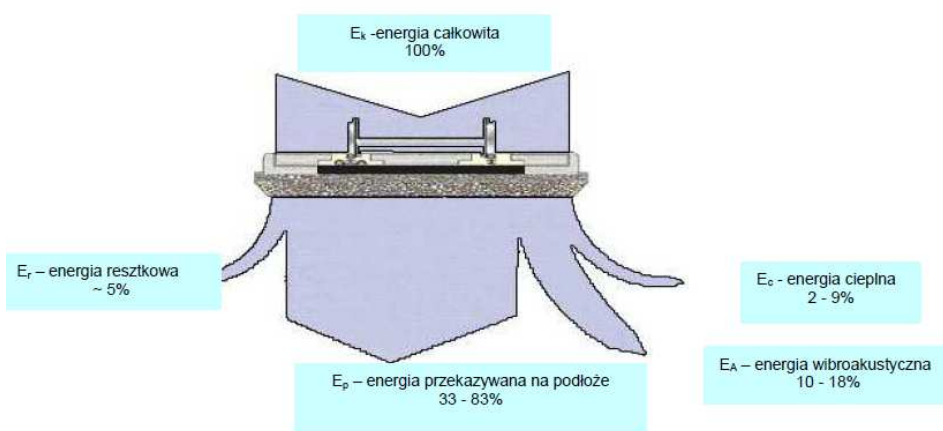

3. Energy balance of classical railroad crossing [3] 


\section{Rules for the selection of the type of the level crossing surface at the crossing by Technical Standards of PKP PLK}

In line with the technical standards of PKP PLK for journeys [2], road pavement on level crossings placed on the market and admitted on the PKP PLK network must have an indefinite admission certificate for use, and for the pavement surfaces placed on the market after October 27, 2015 it is necessary admission to be used in accordance with the SMS PW17 procedure issued by PKP PLK.

In order to improve the quality of the surface being exploited, on the crossings on the PKP PLK network, rules were introduced for the selection of a road and road surface at the crossing, depending on the parameters of the railway and railway line. The principles introduced are aimed at maintaining reliability and operational durability, as well as maintenance and repair susceptibility while increasing economic characteristics, so that the surface at the crossings takes into account the specificity of traffic and location.

A point score of the travel parameters was introduced depending on the position in the line plan and type of sleepers, type of road surface, intensity of the railway load, traffic category, local conditions and type of road surface. A system of values has been introduced by scoring a given pass parameter from 1-5, where 5 sets the preferred surface and 1 is forbidden. Preferred for use are pavement types on crossings that have received the highest score, however, the final decision on the type of surface is taken by the appropriate terrain plant of Railway Lines.

Technical standards of PKP PLK [2] qualify four types of pavement on crossings: integrated (seedless), complex large-size (ballast), complex small-sized (ballast) and classic (ballast).

\section{Examples of surface types on crossings}

Surfaces at level crossings can be divided into three types of structures used in bedding surfaces. The types of railway surface from prestressed concrete and wooden sleepers with fixing of rails for classic and elastic type sleepers as well as ungrounded surfacing have been determined.

The type of classic ballast surfacing is presented on the example of CBP large-size panels. CBP plates are commonly used at level crossings and constitute about $80 \%$ of journeys on railway lines in Poland. The structure consists of PW180 (140), PWS 180 (140), PZ 180 (140), $3 \mathrm{~m}$ long, laid directly on the sleepers or clay block. The advantage of the structure is low price, fast and requiring no special assembly equipment, the disadvantage of the construction is plate pressing. In urban areas - quiet, according to technical standards, CBP type crossings obtained 4 points, as accepted for use [2].

The second type of concrete slabs are complex small-sized (ballasted), for example Mirosław type, smaller than the large-size weight plates of individual elements laid on the surface, ensuring ease of assembly and disassembly. External boards on the track side are arranged by shock absorbers on the foot of the rail, and from the side of the road, through a rubber belt on the supporting beam, fig.4. The disadvantages of this construction are the necessity of pouring the foundation footing under the supporting beam and mounting the external boards to the supporting beams using screws. In the areas of quiet urban development, the results obtained 4 points (accepted) in accordance with technical standards [2]. 


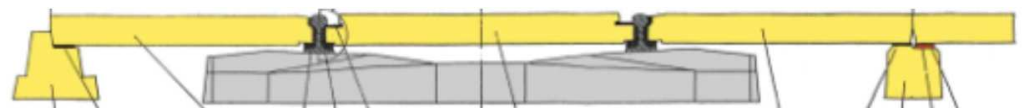

4 Surface type Mirosław [9]

The level crossing surface made of rubber plates as a small-sized joint will be presented on the examples of solutions and types: STRAIL, KOL-DROG and ELASTrack. The STRAIL [7] surfaces consist of two-layer outer and inner panels. The inner layer is made of a vulcanising compound, and the outer layer of rubber has a high class of abrasion resistance. STRAIL type pavement consists of concrete curbs on which panels, cushions and protective plates for moving steel plates for safety wedges are installed. The advantage of the surface is its occurrence in many construction variants. As a result of dynamic tests, a reduction in noise generated by approximately $6 \mathrm{~dB}$ has been demonstrated. The disadvantages of the STRAIL surface are the high price, frequent wearing of the cushions requiring replacement and delamination of the boards with heavy traffic. In the areas of quiet urban development, they obtained 5 points (preferred) in accordance with technical standards [2].

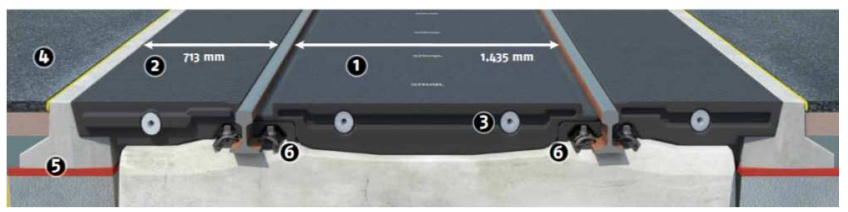

5. Surface type STRAIL, 1 - internal panel, 2, - external panel, 3- fastening system, 4-way connection with the road, 5-curb, 6-rail insert [7]

The surface type KOL-DROG [6] consists of rubber panels, foundation panels, curb foundation and a steel wedge preventing displacement of the boards. The construction of the passage affects the reduction of noise emission, however, the durability of the rubber layer is low and requires frequent replacement of Fig. 6. The plates are connected to the so-called groove, not allowing adjustment of neighboring boards. The solution is more expensive than the construction of reinforced concrete slabs. In the areas of quiet, quiet urban development, the results obtained 5 points (preferred) in accordance with technical standards [2].

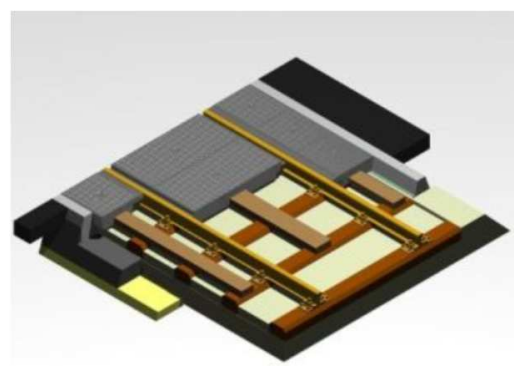

6. Surface type KOL-DROG [6]

The ELASTrack type surface is a rubber surface system for railway crossings manufactured by FTT Wolbrom SA. It is a modular construction that allows the construction 
of a passage of any length (Fig.7). Currently, this type of surface is not used on Polish railway lines. The ELASTrack surface has been approved for use on PKP PLK in April 2016. There is no data on the durability of the structure. In the areas of quiet urban development, it obtained 5 points (preferred) in accordance with technical standards [2].

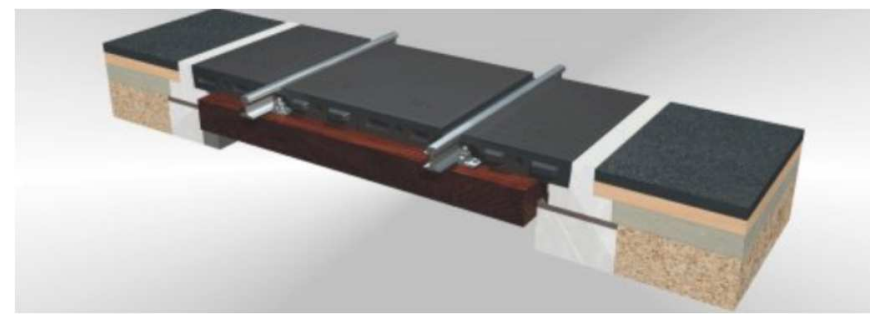

7. Surface type ELASTrack [5]

The road plates manufactured by ZWG Iwiny are a type of surface connecting the structures of reinforced concrete crossing slabs with vibration isolation (Fig.8). The reinforced concrete slabs are connected by means of a flexible connector, which allows for making the surface in a modular form. The upper part of the elastic rubber element constituting the running surface is corrugated to increase the grip of the vehicle wheels. On the length of the rails, a flexible damping element is used, tightly adhering to the neck and foot of the rail. The advantages of the structure are rubber elements that insulate the board from the sleepers and damp vibrations along the rail. The disadvantage of the solution is the unstable corrugated wear layer, and where the water lies in the notches. The price of ZWG Iwiny crossing slabs is much higher than that of reinforced concrete slabs. Test results for ZWG Iwiny: compressive strength $75 \mathrm{MPa}$, bending strength $8.5 \mathrm{MPa}$, absorbability $4 \%$, frost resistance, no loss of mass and changes in strength after 150 cycles. In the areas of quiet, quiet urban development, the results obtained 5 points (preferred) in accordance with technical standards [2].

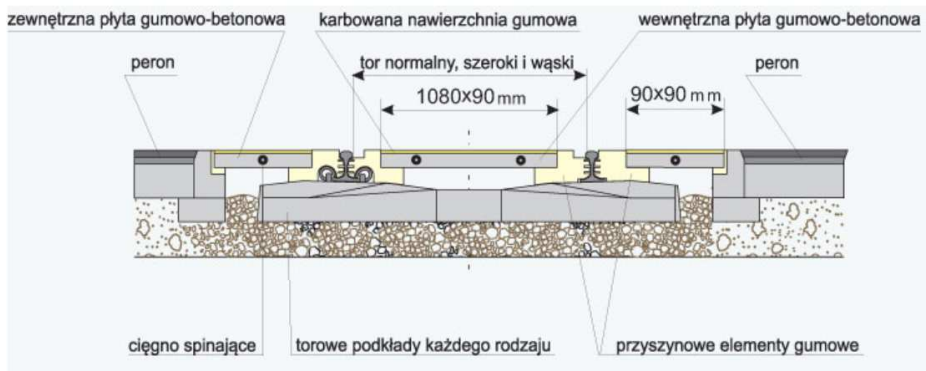

8. Surface type ZWG Iwiny [10]

Level crossings made in non-bed technology are solutions that are based on reinforced concrete prefabricated slabs combining the functions of the road surface and foundation for the railway track (Fig.9). Due to the way of transferring loads from road surface to railway, these are integrated track and rail surface structures (no-bed structure). Non-bedridden rides are a group of solutions that are definitely the most durable and the most durable in terms of axial loads, at the same time creating a problem related to the threshold effect and maintenance. The concrete slab laid on the prepared ground is a supporting structure for the track and road surface. The rails in this system can be fixed in the rail channel by flooding them with synthetic resin or fixed with gussets. Surface systems for uncropped vibration isolation are, among others, monolithic boards of TINES EDILON LC-L [8]. It is an integrated system consisting of prefabricated components: a reinforced concrete plate with shaped rail channels in which rails in the cover (in the ERS system) are placed. The 
disadvantage of the solution is the difficult disassembly of resin-covered rails and the difficult maintenance and repair work as well as the highest construction cost. In the areas of quiet urban development, they obtained 4 points (accepted) in accordance with technical standards [2].

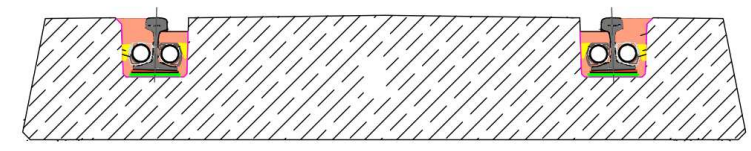

9. Cross-section through an integrated (dirt-free) EDILON LC-L drive [8]

\section{Summary}

The quality of the surface at level crossings is affected by the reliability and durability of the operation as well as maintenance and repair vulnerability and economic characteristics. The impact of maintenance and repair susceptibility and economic characteristics level crossings has been emphasized in the new guidelines for the use of trips on the PKP PLK network. Preferences of using bedding surfaces in urban-quiet areas and on lines with the highest intensity of rail traffic load were shown. The introduction of preferences for the application of bedding surfaces on crossings is caused by economic factors, because bedding surfaces are much cheaper than non-bedding. Maintenance and repair works are also cheaper. In ballast pavements, maintenance and repair, including track geometry, circular road in plan and profile, and replacement of rails, is faster and cheaper compared to non-heap surfaces. On the PKP PLK railway network, rules for the selection of the type of road crossing have been introduced, taking into account the local conditions of road construction. By dividing the urban development into a quiet, normal and undeveloped area, preferring in urban areas - a quiet surface of compacted ballast type walkway, large-size and small-size with vibration isolation [2].

\section{Source materials}

[1] Rozporządzenie Ministra Infrastruktury i rozwoju $\mathrm{z}$ dnia 20.10.2015 z dnia 20 października 2015 r. w sprawie warunków technicznych, jakim powinny odpowiadać skrzyżowania linii kolejowych oraz bocznic kolejowych z drogami i ich usytuowanie

[2] Standardy techniczne PKP PLK tom X - załącznik ST-T10/1 z 31 stycznia 2017r.

[3] Targosz J.: Ograniczenie oddziaływań dynamicznych od dróg kolejowych i samochodowych, Monografia Wyd. KriDM AGH, Kraków 2004

[4] Targosz J.: Wibroizolowane przejazdy na skrzyżowaniach torów z drogami kołowymi, Technika transportu szynowego, 2003

[5] www.fttwolbrom.com

[6] www.koldrog.pl

[7] www.strail.de

[8] www.tinescg.com

[9] www.wps-sa.com.pl

[10] www.zwg.com.pl/ 